\title{
A novel technique for biliary strictures that cannot be passed with a guide wire
}
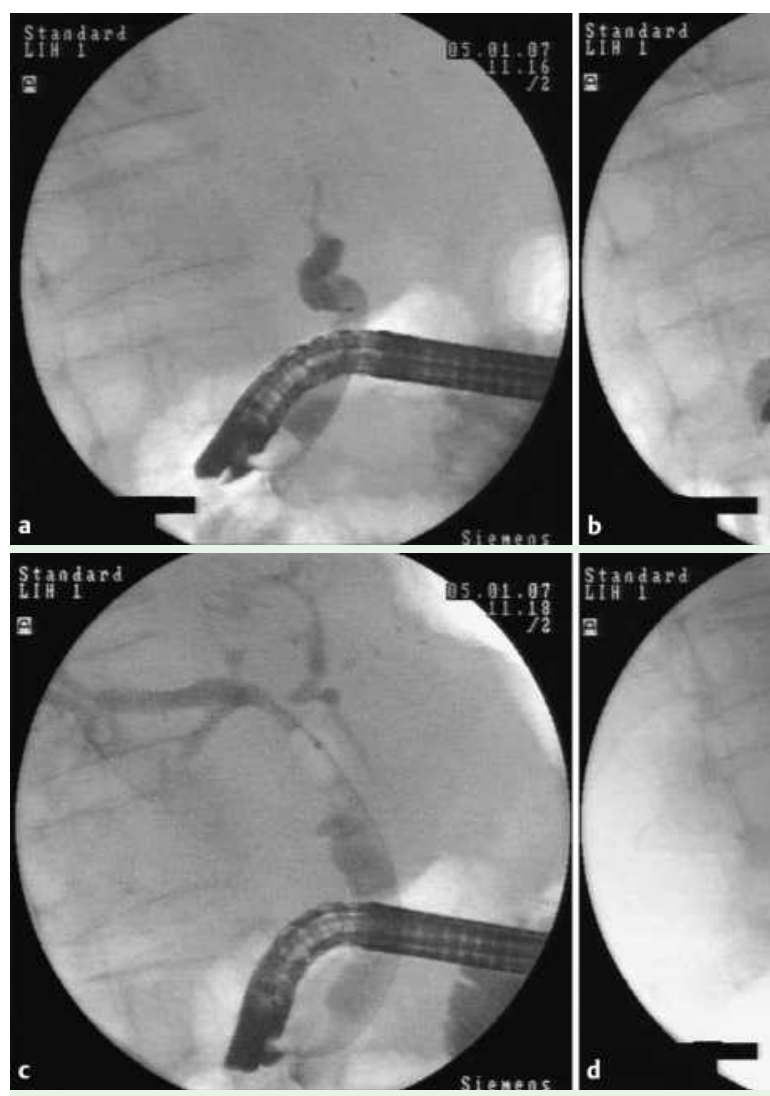

Figure 1 a S-shaped anastomotic stricture. $\mathbf{b}$ The inflated standard balloon near the stricture in the distal part of the common bile duct. Thereafter, it was pulled slowly. $\mathbf{c}$ After the common bile duct had become slightly stretched, it was possible to pass the stricture with the guide wire. $\mathbf{d}$ View following successful placement of a double plastic stent.

Bile leaks and strictures are the main biliary complications diagnosed by endoscopic retrograde cholangiopancreatography (ERCP) in living donor living transplantation (LDLT) patients. Endoscopic management is difficult mainly because of the complexity of duct-toduct reconstruction. Recently, we have experienced five right-lobe LDLT cases with cholangitis in which ERCP revealed S-shaped anastomotic stricture ( $\bullet$ Figure $1 \mathrm{a})$. The S-shaped stricture could not be passed with a guide wire, despite many maneuvers and changing positions of the sphincterotome and standard balloon. However, it became possible to pass the stricture with the guide wire by a novel method; the standard balloon was inflated near the stricture in the distal part of the common bile duct ( $\bullet$ Figure $\mathbf{1 b}$ ). The inflated balloon was pulled slowly. After the common bile duct had become slightly stretched, it was possible to pass the stricture with the guide wire ( Figure $1 \mathbf{c}$ ). Thereafter, we were able to perform balloon dilation and plastic stent placement in all cases ( $\bullet$ Figure $1 \mathbf{d}$ ). We believe that this novel technique is effective for S-shaped anastomotic strictures that cannot be passed with a guide wire.

Endoscopy_UCTN_Code_TTT_1AR_2AG

\section{G. Ersoz, F. Tekin, O. Ozutemiz, O.Tekesin}

Department of Gastroenterology, Ege University Medical School, Izmir, Turkey

Bibliography

DOI 10.1055/s-2007-966559

Endoscopy 2007; 39: E332

(c) Georg Thieme Verlag KG Stuttgart · New York . ISSN 0013-726X

\section{Corresponding author}

\section{F. Tekin, MD}

Ege Universitesi Tip Fakultesi

Gastroenteroloji Bilim Dali

Bornova 35100

Izmir

Turkey

Fax: +90-232-3427764

drtekinfatih@yahoo.com 